\title{
PENILAIAN RISIKO KESEHATAN LINGKUNGAN KECAMATAN ABIANSEMAL, KABUPATEN BADUNG
}

\author{
Ni Ketut Sri Lestari ${ }^{1 *}$, I Made Ady Wirawan ${ }^{2)}$, Pande Putu Januraga ${ }^{2)}$ \\ ${ }^{1)}$ Program Studi Magister Ilmu Lingkungan, Universitas Udayana \\ ${ }^{2)}$ Departemen Kesehatan Masyarakat dan Kedokteran Pencegahan, Fakultas Kedokteran Universitas \\ Udayana \\ *Email: lestaribali4@gmail.com
}

\section{ABSTRACT \\ ENVIRONMENTAL HEALTH RISK ASSESSMENT IN ABIANSEMAL DISTRICT, BADUNG REGENCY}

Environment, a variable that often gets special attention in assessing public health and environmental health, is an effort to prevent disease. Environmental Health Risk Assessment (EHRA) is a comprehensive study about sanitation facilities' conditions and risky behaviors on public health. Abiansemal District is one of the tourist destinations that has a very complex impact, especially on environmental health aspects. Behavior is a highly potential factor for health status, clean and healthy behavior is strongly influenced by the availability of sanitation facilities in order to control physical environmental factors that can harm health. This study determines the Health Risk Index and obtains an overview of the sanitation facilities condition and community behavior that has a risk for environmental health in Abiansemal District, Badung Regency. This study used stratified random sampling using a sample in the Abiansemal subdistrict which has been determined as the target study area. Households to be visited in each village were selected randomly by stratified random sampling. After finding the first household visited, an interview was conducted according to the available questionnaire and after it was completed it was forwarded to neighbors until it found 40 houses per village. SPSS 20.0 is used for the data analysis. The description of sanitation facilities and community behavior that poses a risk to health in strata 1 has the main problem in domestic waste with the highest score of 36, while strata 2 has the main problem in solid waste with a score of 43 and strata 3 has the main problem in domestic wastewater with a score of 45 . Analysis results of the sanitation risk index for the category of low risk/less risky area for strata 1 ( 1 village), the category of high-risk area for Strata 2 (11 villages), and the category of moderate risk area is in Strata 3 (6 villages). The high-risk area is found in Strata 2 (11 villages).

Keywords: EHRA; Environmental health; Abiansemal; Badung.

\section{PENDAHULUAN}

Lingkungan merupakan sebuah variabel yang mendapatkan perhatian khusus dalam penilaian kesehatan masyarakat. Derajat kesehatan masyarakat dapat ditentukan oleh faktor lain disamping faktor lingkungan, seperti perilaku, pelayanan kesehatan dan genetik. Kesehatan lingkungan merupakan upaya yang dilakukan sebagai bentuk pencegahan datangnya penyakit atau gangguan kesehatan akibat risiko yang ditimbulkan lingkungan untuk mendapatkan kualitas sehat pada lingkungan dari berbagai aspek kehidupan yang mungkin terjadi pada manusia. Kesehatan terpadu perlu diupayakan secara menyeluruh yang memiliki tujuan mewujudkan derajat kesehatan bagi masyarakat. Perlu juga dilakukan usaha pembangunan berkelanjutan seperti rangkaian pembangunan yang menyeluruh (pembangunan kesehatan) untuk memenuhi tujuan nasional. 
Tingginya kejadian penyakit di masyarakat yang berbasis lingkungan disebabkan minimnya pengetahuan masyarakat terhadap perilaku hidup bersih dan sehat (PHBS). Perilaku adalah faktor yang paling penting yang dapat berpengaruh pada derajat kesehatan disamping lingkungan, pelayanan kesehatan dan keturunan. Untuk dapat berprilaku hidup bersih dan sehat sangat dipengaruhi dengan ketersediaan fasilitas sanitasi, adanya fasilitas sanitasi kualitas lingkungan dapat terpelihara dan faktor yang merugikan kesehatan pada lingkungan dapat dikendalikan. Fasilitas sanitasi mutlak harus tersedia di rumah tangga maupun tempattempat umum, sehingga lingkungan dapat terpelihara dan dapat menekan kejadian penyakit yang berbasis lingkungan di masyarakat. Interaksi dari perilaku dengan kualitas pelayanan kesehatan dengan faktor dominan dari lingkungan seperti sarana air bersih, adanya vektor penyakit, penanganan sampah, dan pembuangan tinja dapat berpotensi menyebabkan diare (Sudaryat, 2007; Kumala, 2011).

Penilaian risiko kesehatan lingkungan Environmental Health Risk Assessment (EHRA) adalah analisis yang menitikberatkan pada kondisi fasilitas sanitasi dan perilaku masyarakat yang memiliki resiko terhadap kesehatan. Studi EHRA meneliti tentang sumber air bersih (SAB), jamban, tempat sampah rumah tangga dan saluran pembuangan air limbah (SPAL) rumah tangga. Indikator perilaku masyarakat adalah kebiasaan cuci tangan pakai sabun (CTPS), pengelolaan sampah dalam rumah tangga, dan kebiasaan buang air besar. Studi ini juga melakukan pemetaan risiko kesehatan lingkungan (IUWASH, 2011).

Kecamatan Abiansemal adalah sebuah daerah tujuan wisata di Kabupaten Badung dan membawa dampak yang sangat kompleks khususnya pada aspek kesehatan lingkungan. Tumbuhnya pemukiman baru yang padat dan masih adanya kejadian penyakit di masyarakat yang berbasis lingkungan, disebabkan karena tidak semua masyarakatnya dapat berperilaku hidup bersih dan sehat. Perilaku merupakan salah satu faktor yang berpengaruh terhadap derajat kesehatan disamping lingkungan, pelayanan masyarakat dan keturunan. Untuk dapat berperilaku hidup bersih dan sehat sangat dipengaruhi oleh ketersediaan fasilitas sanitasi, dengan adanya fasilitas sanitasi kualitas lingkungan dapat terpelihara dan faktor-faktor lingkungan fisik yang dapat merugikan kesehatan dapat dikendalikan. Fasilitas sanitasi mutlak harus tersedia di rumah tangga maupun tempat-tempat umum sehingga lingkungan dapat terpelihara dengan baik dan juga menekan kejadian penyakit yang berbasis lingkungan di masyarakat. Upaya pencapaian derajat kesehatan yang optimal di Kecamatan Abiansemal sangat dipengaruhi oleh kondisi-kondisi tersebut.

\section{METODOLOGI}
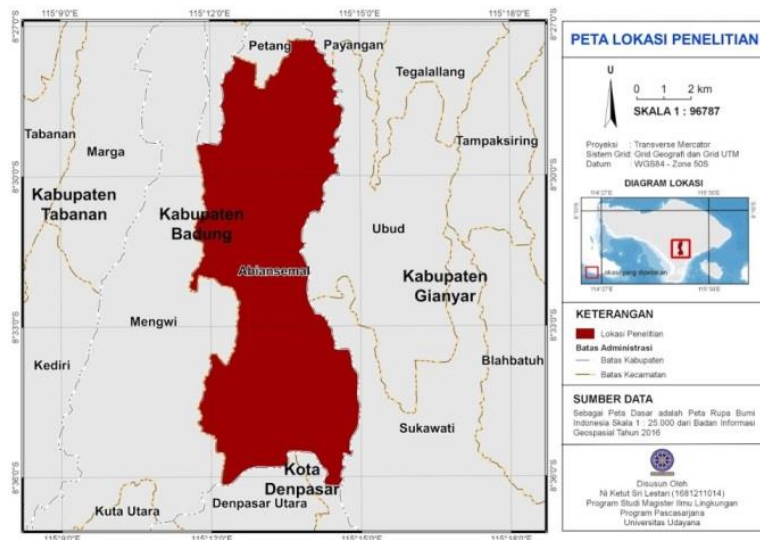

Gambar 1.

Peta Lokasi Penelitian

Penelitian ini adalah penelitian kuantitatif untuk menilai risiko kesehatan lingkungan di Kecamatan Abiansemal, Kabupaten Badung. Dalam penelitian ini digunakan metode observasi dan wawancara yang dilakukan dengan pendekatan survei deskriptif menggunakan metode EHRA (Envinronmental Health Risk Assessment). Kondisi dari fasilitas sanitasi dan higienitas yang akan mempengaruhi kesehatan masyarakat dalam skala rumah tangga akan digambarkan dalam studi EHRA. Selain itu, EHRA juga dapat menggambarkan tingkat risiko fasilitas sanitasi dan perilaku masyarakat di tingkat kabupaten, kota, kelurahan ataupun desa.

Populasi dalam kajian ini merupakan rumah tangga yang ada di Kecamatan Abiansemal, sedangkan responden dalam 
kajian ini adalah ibu/kepala rumah tangga yang sehat jasmani maupun kejiwaan. Sampel penelitian ditetapkan pada daerah dari populasi yang sudah direncanakan sebagai tujuan area penelitian. Akan dilakukan stratifikasi untuk memberikan klasifikasi desa/kelurahan yang sudah di sesuaikan dengan tingkat risiko dari kesehatan pada lingkungan yang dilihat dari faktor demografi serta geografi.

Strata ditetapkan berdasarkan 4 (empat) kriteria utama berdasarkan Program PPSP merupakan strata yang harus diikuti semua Pokja Sanitasi kabupaten/kota meneliti Studi EHRA. Kriterianya terdiri dari kepadatan jumlah penduduk, angka kemiskinan, daerah/wilayah yang teraliri saluran/sungai saluran irigasi/ drainase, serta daerah rawan banjir. Proses pengolahan dan analisis data dilakukan setelah semua data terkumpul. Pengolahandan analisis data dilakukan secara deskriptif dan univariat.

\subsection{Pengolahan data}

Pengolahan data dilakukan dalam beberapa tahapan berupa editing, coding, entry data, dan tabulating. Editing merupakan tahap pemeriksaan data yang telah berhasil dikumpulkan. Tahap Editing bertujuan untuk mengoreksi kekeliruan dan kekurangan data yang ada pada catatan lapangan. Coding nerupakan proses pemberian inisial tertentu pada setiap data. Inisial ini merupakan sebuah kode yang berupa angka atau huruf ataupun kombinasinya untuk dapat membedakan identitas data. Entry data diperlukan untuk memasukan data yang sudah terkumpul ke dalam satu database untuk pengolahan data selanjutnya. Tabulating merupakan tahap penyusunan data dalam bentuk tabel sesuai dengan keperluan analisis.

\subsection{Analisis data}

Analisis data dilakukan secara deskriptif dan univariat. Penentuan IRKL didapatkan dalam beberapa tahapan sebagai berikut.

a) Indeks Risiko Kesehatan Lingkungan

Penghitungan IRKL awal dilakukan dengan mempersentasekan setiap komponen yang menjadi sumber dan peluang paparan bahaya beserta komponen didalamnya per penduduk RT. Dengan demikian, IRKL dapat ditentukan dengan menggunakan persamaan berikut.

$$
\text { Indeks risiko }=\frac{\text { Sumber bahaya }}{\sum \text { Penduduk per } R T} \times 100 \%(1)
$$

b) Kalkulasi Indeks Risiko Kesehatan Lingkungan

Tahap kedua adalah pembobotan komponen sumber bahaya dan peluang tingkat paparan bahaya. Pembobotan dilakukan dengan memberi bobot $100 \%$ pada setiap sumber bahaya dan peluang tingkat paparan bahaya. Hal ini dilakukan dengan ketentuan bobot $100 \%$ dibagi berdasarkan jumlah komponen dalam variabel bahaya dan peluang tingkat paparan bahaya. Kemudian dilanjutkan dengan takap penghitungan menggunakan persamaan berikut.

\section{Kalkulasi $=$ \\ persentase indeks risiko (\%) $\times$ \\ bobot per sumber bahaya (\%)}

c) Kumulatif Indeks Risiko Kesehatan Lingkungan

Penghitungan kumulatif dilakukan dengan menjumlahkan IRKL berdasarkan perhitungan nilai yang didapatkan dari hasil langkah sebelumnya. Setiap komponen variabel yang menjadi sumber bahaya dan peluang tingkat paparan bahaya dijumlahkan untuk mendapatkan nilai kumulatif. Nilai kumulatif kemudian digunakan untuk menentukan kategori risiko kesehatan lingkungan dengan mengukur interval perhitungan total indeks risiko maksimum dan total indeks risiko minimum. Nilai interval dapat diperoleh dengan menggunakan persamaan berikut.

$$
\begin{aligned}
& \text { Interval }= \\
& \frac{\text { Nilai indeks max }- \text { nilai indeks min }}{\sum \text { kategori risiko }}
\end{aligned}
$$

Tahap selanjutnya adalah menentukan batas bawah dan batas atas dengan menjumlahkan nilai risiko minimum dan interval. Dari penjumlahan ini memperoleh batas atas untuk kategori pertama. Kemudian kategori kedua batas bawah ditentukan dengan menjumlahkan batas bawah dengan interval, dan berlanjut hingga sampai kategori ketiga. 
d) Menentukan kategori area risiko skor IRKL dengan menyesuaikan nilai IRKL dalam rentan batas atas dan batas bawah pada kategori pertama hingga ketiga.

e) Menghitung kejadian diare dilakukan dengan cara :

$$
\begin{aligned}
& n= \\
& \frac{\sum \text { kejadian kasus diare }}{\sum \text { penduduk yang dikunjungi }} X 100 \%
\end{aligned}
$$

Angka Kejadian Diare dalam dua minggu didapatkan dari jumlah kasus diare dalam dua minggu dibagi dengan jumlah populasi yang dikunjungi.

\section{HASIL DAN PEMBAHASAN}

\subsection{Gambaran Umum Daerah Penelitian}

Menurut BPS Kabupaten Badung (2021) laju pertumbuhan penduduk pada tahun 2010-
2020 (data antar sensus) di kecamatan Abiansemal terdapat peningkatan laju pertumbuhan dengan rata-rata $1,12 \%$ per tahun. Hal ini menunjukkan bahwa kecamatan Abiansemal telah menjadi tumpuan harapan dari para migran yang datang ke Bali. Kecamatan Abiansemal terletak di Kabupaten Badung, memiliki 18 desa dengan total luas $69,01 \mathrm{Km}^{2}$. Jumlah penduduk kecamatan Abiansemal per tahun 201992.34 ribu penduduk (BPS Kabupaten Badung 2020).

Kecamatan Abiansemal adalah suatu daerah tujuan wisata di Kabupaten Badung yang membawa dampak khususnya pada aspek kesehatan lingkungan. Tumbuhnya pemukiman baru yang padat dan terjadinya kejadian penyakit di masyarakat yang berbasis lingkungan disebabkan karena masyarakat yang belum melaksanakan PHBS.
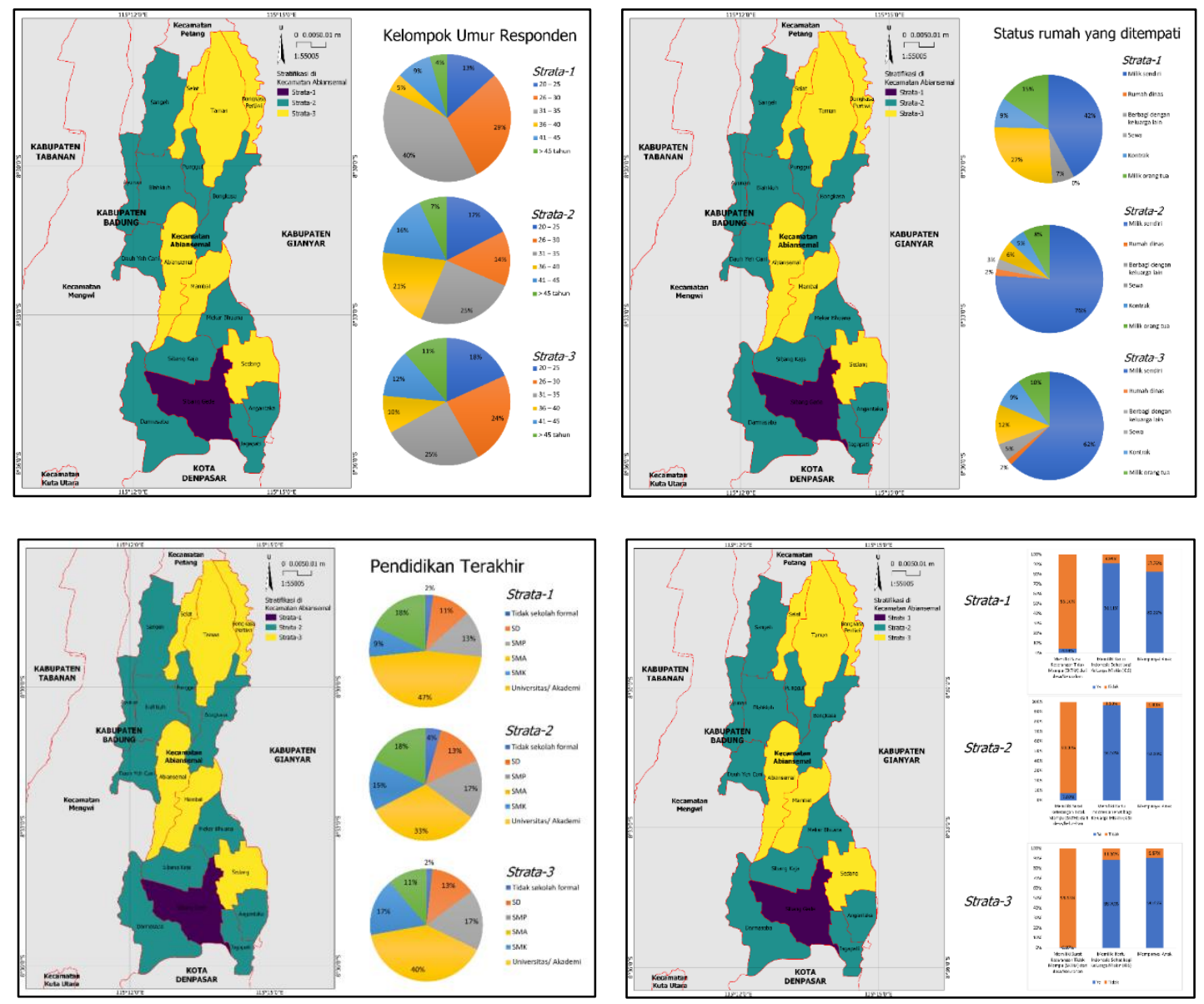

Gambar 2.

Informasi responden penelitian

Responden pada penelitian ini adalah ibu rumah tangga atau anak perempuan yang telah menikah. Gambar 1 menunjukkan bahwa responden yang menjadi narasumber dengan 
rentang umur terbanyak yaitu pada usia 31 35 tahun sebanyak $27 \%$ dan dengan rentang umur $>45$ tahun merupakan jumlah responden terendah yaitu sebanyak $8 \%$. Dari keseluruhan responden menunjukkan bahwa kepemilikan rumah sendiri adalah yang terbanyak yaitu sebesar $62,5 \%$. Jika melihat dari status pendidikan dapat dilihat sebanyak $36,7 \%$ merupakan tingkat pendidikan SMA dan yang terbanyak selanjutnya Universitas/Akademi, SMK, dan SMP. Hal ini dapat dilihat dari responden bahwa pendidikan sudah menjadi prioritas yang cukup tinggi meskipun baru sampai tahap SMA. Sebesar 4,8\% responden memiliki Surat Keterangan Tidak Mampu (SKTM) sedangkan yang tidak memiliki SKTM sebanyak 95,2\% hal ini menunjukkan hanya sedikit responden yang masuk ke dalam kategori miskin sesuai dengan kondisi Kabupaten Badung yang memiliki angka kemiskinan cukup rendah yaitu sebesar 2,02\% pada tahun 2020 (BPS Kab. Badung). Hasil studi juga menunjukkan bahwa sebanyak 91,3\% responden yang memiliki anak.

\subsection{Kondisi Fasilitas Sanitasi dan Prilaku}

\subsubsection{Pengelolaan Sampah dalam Rumah Tangga}

Hasil dari studi EHRA untuk area beresiko pengelolaan sampah dalam rumah tangga menggambarkan pengelolaan persampahan yang beresiko menimbulkan permasalahan berdasarkan pendapat masyarakat. Meliputi beberapa hal antara lain 1) untuk pengelolaan sampah sebanyak $51,3 \%$ responden menjawab tidak memadai dan hanya 48,7\% yang mengatakan aman dan cukup memadai. Hal ini menunjukkan masih banyak masyarakat yang beranggapan bahwa pengelolaan sampah di daerah yang menjadi lingkup studi EHRA tidak memadai dan perlunya ada peningkatan pelayanan. Persentase yang menyumbang pelayanan tidak memadai ada pada strata 2 yaitu sebesar $69,8 \%$ dikarenakan daerah yang menjadi lokasi studi tidak mendapat pelayanan yang memadai sehingga pengelolaan sampah dilakukan sendiri oleh rumah tangga masingmasing. Variabel ke-2 adalah frekuensi pengangkutan sampah sebesar $8,7 \%$ responden menjawab tidak memadai dan sebesar $91,3 \%$ responden mengatakan cukup memadai. Variabel ke-3 adalah ketepatan waktu pengangkutan sampah yang berkaitan erat dengan variabel 2, jika ada frekuensi pengangkutan sampah maka adanya ketepatan waktu pengangkutan yang hanya ada di strata 1 dan strata 3. Hasil analisis EHRA menunjukkan sebesar $90,5 \%$ responden menjawab tidak tepat waktu dan sebesar 9,5\% responden mengatakan pengangkutan sampah sudah tepat waktu. Variabel terakhir dalam area beresiko persampahan yaitu pengolahan sampah setempat sebanyak 94,3\% responden menjawab tidak mengolah sampah secara mandiri dan sisanya $5,7 \%$ melakukan pengolahan sampah secara mandiri pada masing-masing rumah tangga.

Membuang sampah di biopori di halaman atau di luar rumah disebutkan menjadi cara yang aman menurut beberapa ahli. Alternatif membuang sampah di biopori tidak berlaku di kawasan yang tergolong pulau kecil, terlebih jika tidak terdapat sarana pengangkutan sampah (Tim National Geographic, 2013). Sebagai bentuk dukungan untuk mengurangi penumpukan sampah sangat diperlukan perilaku masyarakat untuk mengolah sampah pada skala rumah tangga. Jumlah timbulan sampah dapat dikurangi dengan memilah menjadi 2 jenis yaitu sampah organik dan anorganik, setelah terpilah dilakukan pengolahan kembali. Pengolahan yang tepat dan bisa dilakukan oleh masyarakat yaitu dengan menggunakan kembali atau membuat produk baru barang tersebut yang memiliki nilai jual. Membuang sampah dengan tanpa pengolahan akan menjadi pencemar lingkungan dan akan berbahaya bagi masyarakat. Hal tersebut dapat menaikkan risiko pencemaran air laut atau pada air rumah tangga, dan bibit penyakit akan semakin tinggi pula.

Limbah dari kegiatan rumah tangga yang merupakan limbah organik akan terdegradasi oleh mikroba yang akan menimbulkan bau busuk, karena proses terurainya limbah tersebut menjadi bagian yang lebih kecil yang akan melepaskan gas yang menimbulkan bau. Aktivitas tersebut akan berdampak pada kesehatan yang akan menimbulkan berbagai macam penyakit seperti penyakit yang ditimbulkan oleh tikus, diare yang berasal dari 
pengolahan sampah yang tidak tepat (Hasibuan, 2016).

Di Kecamatan Abiansemal terdapat tempat usaha pengelolaan sampah swasta yang ada untuk membantu pengelolaan sampah masyarakat Abiansemal dan ada juga secara swadaya oleh banjar sekaligus sebagai media komunikasi penyuluhan tentang pengelolaan sampah yang baik kepada masyarakat untuk kebersihan lingkungan dan kesehatan masyarakat, juga menambah pendapatan perekonomian masyarakat dari pemilahan sampah dalam rumah tangga.

\subsubsection{Pembuangan Air Kotor/ Limbah Tinja Manusia dan Lumpur Tinja}

Indikasi penggunaan jamban yang tidak aman digunakan untuk lingkungan rumah tangga dapat dilihat dari tangki septik yang tidak pernah dikuras. Air dan lumpur didalam tangki septik dapat merembes dan mengakibatkan pencemaran air dan tanah. Selain karena rembesan air dan lumpur ke lingkungan, pembuangan tinja dalam tangki septik yang dilakukan sembarangan akan mencemari lingkungan (Rahma, 2003). Kejadian tersebut akan menjadikan risiko kejadian penyakit akibat infeksi bakteri atau penyakit lain semakin besar.

Tangki septik yang kurang layak menyebabkan peningkatan pencemaran air tanah. Hingga saat ini masih terdapat tangki septik yang kurang ideal yang berada di area perkotaan padat penduduk (Badan Perencanaan Pembangunan Nasional, 2006). Seiring dengan pertambahan tangki septik disetiap bangunan dan didukung dengan Sebagian besar tangki septik yang tidak sesuai dengan standar teknis yang ditetapkan sehingga mengakibatkan kualitas air tanah menurun (Badan Perencanaan Pembangunan Nasional, 2006).

Tabel 1. Area Beresiko Air Limbah Domestik Berdasarkan Hasil Studi EHRA

\begin{tabular}{|c|c|c|c|c|c|c|c|c|c|}
\hline \multirow{3}{*}{ Kategori } & \multirow{3}{*}{ Variabel } & \multicolumn{6}{|c|}{ Strata Desa/Kelurahan } & \multicolumn{2}{|c|}{ Total } \\
\hline & & \multicolumn{2}{|c|}{1} & \multicolumn{2}{|c|}{2} & \multicolumn{2}{|c|}{3} & \multirow[b]{2}{*}{$\mathrm{n}$} & \multirow{2}{*}{$\%$} \\
\hline & & $\mathrm{n}$ & $\%$ & $\mathrm{n}$ & $\%$ & $\mathrm{n}$ & $\%$ & & \\
\hline \multirow{2}{*}{$\begin{array}{l}\text { Tangki septik suspek } \\
\text { aman }\end{array}$} & Tidak aman & 2 & 4,6 & 26 & 10,2 & 0 & 0 & 28 & 8,2 \\
\hline & Suspek aman & 41 & 95 & 170 & 86,8 & 102 & 100 & 313 & 91,8 \\
\hline \multirow{4}{*}{$\begin{array}{l}\text { Pencemaran karena } \\
\text { pembuangan isi tangki } \\
\text { septik } \\
\text { Pencemaran karena } \\
\text { SPAL }\end{array}$} & Tidak, aman & 0 & 0 & 26 & 10,2 & 3 & 3 & 29 & 8,4 \\
\hline & Ya, aman & 45 & 100 & 170 & 86,8 & 99 & 97 & 314 & 91,6 \\
\hline & Tidak aman & 17 & 37,8 & 5 & 4 & 20 & 20,2 & 42 & 15,6 \\
\hline & Ya, aman & 28 & 62,2 & 121 & 96 & 79 & 79,8 & 228 & 84,4 \\
\hline
\end{tabular}

Tabel 1 menunjukkan area beresiko air limbah domestik untuk tangki septik suspek tidak aman sebesar 8,2\% dan dinyatakan aman sebesar $91,8 \%$. Untuk variable pencemaran karena pembuangan tangki septik hampir pada semua strata menunjukkan tidak aman sebesar $8,4 \%$ artinya mengalami pencemaran dan yang tidak mengalami pencemaran atau aman sebesar 91,6\%. Persentase pencemaran yang cukup tinggi memerlukan penangan lebih lanjut untuk mengatasi permasalahan pencemaran yang ditimbulkan oleh pembuangan isi tangki septik. Persentase pencemaran karena SPAL yang tidak aman sebesar $15,6 \%$ dan yang aman sebesar $84,4 \%$.

\subsubsection{Drainase Lingkungan/ Selokan Sekitar Rumah dan Banjir}

Hasil studi EHRA menunjukkan permasalahan pada drainase lingkungan/selokan di sekitar rumah serta banjir disajikan secara lengkap pada hasil wawancara dari responden yang dijadikan sampel dalam penelitian ini. Hasil wawancara dari responden menunjukkan gambaran area beresiko dalam hal drainase lingkungan/genangan air di Kecamatan Abiansemal Badung ditunjukkan pada Tabel 2. Hasil analisa area beresiko genangan air sebesar 83,3\% tidak ada genangan air dan hanya $16,7 \%$ yang ada genangan air atau terjadi banjir. 
Tabel 2. Area Beresiko Genangan Air

\begin{tabular}{|c|c|c|c|c|c|c|c|c|c|}
\hline \multirow{3}{*}{\multicolumn{2}{|c|}{ Genangan Air }} & \multicolumn{6}{|c|}{ Strata Desa/Kelurahan } & \multicolumn{2}{|c|}{ Total } \\
\hline & & \multicolumn{2}{|c|}{1} & \multicolumn{2}{|c|}{2} & \multicolumn{2}{|c|}{3} & \multirow[b]{2}{*}{$\mathrm{n}$} & \multirow[b]{2}{*}{$\%$} \\
\hline & & $\mathrm{n}$ & $\%$ & $\mathrm{n}$ & $\%$ & $\mathrm{n}$ & $\%$ & & \\
\hline \multirow[t]{2}{*}{ Adanya genangan air } & $\begin{array}{l}\text { Ada genangan air } \\
\text { (banjir) }\end{array}$ & 11 & 28,9 & 19 & 10 & 24 & 25 & 54 & 16,7 \\
\hline & Tidak ada genangan air & 27 & 71,1 & 171 & 90 & 72 & 75 & 270 & 83,3 \\
\hline
\end{tabular}

Air yang dibuang dalam saluran drainase harus bersifat tidak membahayakan agar tidak menjadi sumber pencemar karena akan mengalirkan air di kawasan yang terbuka. Air buangan melalui saluran selokan rumah tangga/sarana umum lain yang tidak berbahaya dan bukan bersikap pencemar bisa dibuang langsung ke selokan. Air yan baku mutunya sudah memenuhi syarat yang bisa masuk dalam saluran selokan, agar lingkungan tidak tercemar (Suripin, 2004).

\subsubsection{Pengelolaan Air Minum Rumah Tangga}

Dari Tabel 3 dapat dilihat untuk variabel sumber air terlindungi $86,7 \%$ sumber air berasal dari sumber air terlindungi dan 13,3\% berasal dari sumber air yang tidak terlindungi. Variabel ke-2 yaitu Penggunaan sumber air tidak terlindungi sebesar $87 \%$ berada dalam kategori aman dan $13 \%$ saja yang tidak aman. Variabel terakhir untuk kelangkaan air sebesar $82,3 \%$ tidak pernah mengalami dan $17,7 \%$ pernah mengalami kelangkaan air. Hal ini menunjukkan sumber air di Kecamatan Abiansemal masih cukup memadai baik dari sumber air terlindungi dan sumber air tidak terlindungi serta jarang terjadi kelangkaan air.

Dalam wawancara secara lisan dengan beberapa orang di tempat pengambilan air di beberapa tempat pengambilan air di mata air, masih ada masyrakat mengkonsumsi air langsung dari mata air yang ditampung tanpa direbus terlebih dahulu, mereka mengganggap kualitas air yang mereka ambil setara dengan mengkonsumsi air mineral dalam kemasan. Hal ini mempunyai potensi ternjadinya penyakit diare serta penyakit lainnya.

Untuk hal ini perlu ditingkatkan penyuluhan tentang konsumsi air yang digunakan sehari-hari kepada masyarakat kesehatan mereka dan perlu juga ditambahkan spanduk yang ditaruh pada tempat penampungan mata air yang diambil oleh masyarakat tentang cara konsumsi air yang sehat. Pengawasan rutin terhadap sarana air bersih serta membina masyarakat mengenai pengolahan air minum dan kerjasama dengan sektor PU dan PDAM sangat diperlukan untuk program penyediaan air bersih. Untuk pemeriksaan air yang ada di wilayah Kecamatan Abiansemal sudah pula dilakukan pemeriksaan air baik itu air dalam tanah, PDAM, mata air kolaborasi antara Dinas Kesehatan Provinsi, Pemerintah Kabupaten Badung dan Puskesmas di wilayah Kecamatan Abiansemal.

\subsubsection{Perilaku Higiene dan Sanitasi}

Tabel 4 menunjukkan beberapa variabel terkait perilaku hygiene dan sanitasi masyarakat. 57,6\% responden mengatakan CTPS di lima waktu tidak penting dan sebanyak $42,4 \%$ yang menjawab penting. Sebanyak $81,4 \%$ lantai dan dinding jamban yang terbebas dari tinja dan $18,6 \%$ tidak bebas dari tinja. Kondisi jamban yang bebas dari kecoa dan lalat $80,1 \%$ dan yang masih terdapat kecoa dan lalat sebesar $11,9 \%$. Apabila menggunakan tipe WC duduk maka keberfungsian penggelontor sebesar $88,1 \%$ dan yang tidak berfungsi $11,9 \%$. Penggunaan sabun di sekitar jamban sebesar 87,2\% dan yang tidak ada sabun di sekitar jamban sebesar $12,8 \%$. Sebanyak $4,1 \%$ terjadi pencemaran pada wadah penyimpanan dan penenganan air serta $95,9 \%$ terbebas dari pencemaran sehingga aman digunakan sebagai sumber air bersih. Untuk perilaku BABS sebesar 23,8\% dan yang tidak memiliki perilaku BABS sebesar $76,2 \%$. 
Tabel 3. Area Beresiko Sumber Air Bersih

\begin{tabular}{|c|c|c|c|c|c|c|c|c|c|}
\hline \multirow{3}{*}{ Variabel } & \multirow{3}{*}{ Kategori } & \multicolumn{6}{|c|}{ Strata Desa/Kelurahan } & \multicolumn{2}{|c|}{ Total } \\
\hline & & \multicolumn{2}{|l|}{1} & \multicolumn{2}{|l|}{2} & \multicolumn{2}{|l|}{3} & \multirow[b]{2}{*}{$\mathrm{n}$} & \multirow{2}{*}{$\%$} \\
\hline & & $\mathrm{n}$ & $\%$ & $\mathrm{n}$ & $\%$ & $\mathrm{n}$ & $\%$ & & \\
\hline \multirow[t]{2}{*}{$\begin{array}{l}\text { Sumber air } \\
\text { terlindungi }\end{array}$} & $\begin{array}{l}\text { Tidak, sumber air } \\
\text { berisiko tercemar }\end{array}$ & 1 & 2,6 & 18 & 9,2 & 26 & 24,8 & 45 & 13,3 \\
\hline & $\begin{array}{l}\text { Ya, sumber air } \\
\text { terlindungi }\end{array}$ & 38 & 97,4 & 177 & 90,8 & 79 & 75,2 & 294 & 86,7 \\
\hline \multirow{2}{*}{$\begin{array}{l}\text { Penggunaan } \\
\text { sumber air tidak } \\
\text { terlindungi. }\end{array}$} & Tidak Aman & 0 & 0 & 12 & 6,2 & 32 & 30,5 & 44 & 13 \\
\hline & Ya, Aman & 39 & 100 & 183 & 93,8 & 73 & 69,5 & 295 & 87 \\
\hline \multirow[t]{2}{*}{ Kelangkaan air } & $\begin{array}{l}\text { Mengalami } \\
\text { kelangkaan air }\end{array}$ & 0 & 0 & 38 & 19,5 & 22 & 21,0 & 60 & 17,7 \\
\hline & $\begin{array}{l}\text { Tidak pernah } \\
\text { mengalami }\end{array}$ & 39 & 100 & 157 & 80,5 & 83 & 79,0 & 279 & 82,3 \\
\hline
\end{tabular}

Tabel 4. Area Beresiko Perilaku Higiene dan Sanitasi Berdasarkan Hasil Studi EHRA

\begin{tabular}{|c|c|c|c|c|c|c|c|c|c|}
\hline \multirow{3}{*}{ Kategori } & \multirow{3}{*}{ Variabel } & \multicolumn{6}{|c|}{ Strata Desa/Kelurahan } & \multicolumn{2}{|c|}{ Total } \\
\hline & & \multicolumn{2}{|l|}{1} & \multicolumn{2}{|l|}{2} & \multicolumn{2}{|l|}{3} & \multirow[b]{2}{*}{$\mathrm{n}$} & \multirow[b]{2}{*}{$\%$} \\
\hline & & $\mathrm{n}$ & $\%$ & $\mathrm{n}$ & $\%$ & $\mathrm{n}$ & $\%$ & & \\
\hline \multirow[t]{2}{*}{ CTPS di lima waktu penting } & Tidak & 6 & 15,4 & 172 & 90,5 & 20 & 17,4 & 198 & 57,6 \\
\hline & $\mathrm{Ya}$ & 33 & 84,6 & 18 & 9,5 & 95 & 82,6 & 146 & 42,4 \\
\hline \multirow{2}{*}{$\begin{array}{l}\text { Lantai dan dinding jamban } \\
\text { bebas dari tinja }\end{array}$} & Tidak & 12 & 30,8 & 44 & 23,2 & 8 & 7 & 64 & 18,6 \\
\hline & Ya & 27 & 69,2 & 146 & 76,8 & 107 & 93 & 280 & 81,4 \\
\hline \multirow{4}{*}{$\begin{array}{l}\text { Jamban bebas dari kecoa dan } \\
\text { lalat } \\
\text { Keberfungsian penggelontor. }\end{array}$} & Tidak & 11 & 28,2 & 13 & 6,8 & 17 & 14,8 & 41 & 11,9 \\
\hline & $\mathrm{Ya}$ & 28 & 71,8 & 177 & 93,2 & 98 & 85,2 & 303 & 88,1 \\
\hline & Tidak & 11 & 28,2 & 9 & 4,7 & 21 & 18,3 & 41 & 11,9 \\
\hline & $\begin{array}{l}\text { Ya, } \\
\text { berfungsi }\end{array}$ & 28 & 71,8 & 181 & 95,3 & 94 & 81,7 & 303 & 88,1 \\
\hline \multirow{2}{*}{$\begin{array}{l}\text { Ada sabun di dalam atau di } \\
\text { dekat jamban }\end{array}$} & Tidak & 1 & 2,6 & 17 & 8,9 & 26 & 22,6 & 44 & 12,8 \\
\hline & $\mathrm{Ya}$ & 38 & 97,4 & 173 & 91,1 & 89 & 77,4 & 300 & 87,2 \\
\hline \multirow{2}{*}{$\begin{array}{l}\text { Pencemaran pada wadah } \\
\text { penyimpanan dan } \\
\text { penanganan air }\end{array}$} & Ya, tercemar & 0 & 0 & 10 & 5,3 & 4 & 3,5 & 14 & 4,1 \\
\hline & $\begin{array}{l}\text { Tidak } \\
\text { tercemar }\end{array}$ & 39 & 100 & 180 & 94,7 & 111 & 96,5 & 330 & 95,9 \\
\hline \multirow[t]{2}{*}{ Perilaku BABS } & Ya, BABS & 15 & 38,5 & 39 & 20,5 & 28 & 24,3 & 82 & 23,8 \\
\hline & Tidak & 24 & 61,5 & 151 & 79,5 & 87 & 75,7 & 262 & 76,2 \\
\hline
\end{tabular}

Masalah kebersihan dikarenakan pencemaran tinja (feses) pada sumber air dan lain-lain merupakan sumber yang utama penyebaran virus, bakteri, dan patogen yang menyebabkan penyakit diare. Rute pencemaran hingga kontaminasi bisa sampai ke dalam mulut manusia dan juga balita yaitu dengan 4F melalui air, tanah, hewan kotor, dan jari (ISSDP, 2007). Upaya yang bisa dilakukan manusia untuk memutus rute tersebut adalah dengan cara mencuci tangan dengan sabun. Curtis (2001) mengatakan bahwa penyakit diare dapat menurun $42-47 \%$ dengan mempraktekkan cuci tangan menggunakan sabun, dan cara tersebut bisa menyelamatkan satu juta anak di dunia.

Beberapa literatur mengatakan jika fasilitas sanitasi yang bersih mampu mengurangi penyebaran penyakit yang menyebabkan penyakit diare dengan memblok pencemaran lingkungan dikarenakan 
Penilaian Risiko Kesehatan Lingkungan...

terkontaminasi kotoran manusia. Fasilitas sanitasi juga perlu ditingkatkan agar dapat mengurangi kejadian diare hingga 36\%.

Beberapa peneliti mengatakan kejadian diare berukurang sebesar $30 \%$ dengan penggunaan jamban efektif (Rahma, 2003).

Perubahan perilaku melalui strategi STBM merupakan upaya yang dapat ditempuh untuk meningkatkan akses sanitasi di Puskesmas wilayah Kecamatan Abiansemal. Dengan demikian masyarakat dangat diharapkan dapat mengakses jamban sehat dan bisa membangun di kawasan rumah sendiri.
[Ni Ketut Sri Lestari, dkk]

\subsubsection{Kejadian Penyakit Diare}

Penelitian ini juga mengajukan pertanyaan mengenai kejadian diare pada responden. Tabel 5 dan 6 menunjukkan frekuensi waktu dan kejadian penyakit diare di Kecamatan Abiansemal. Tabel 5 menunjukkan rentang waktu paling dekat terkena penyakit diare $26,9 \%$ dari total responden mengatakan tidak pernah terkena penyakit diare. Tabel 6 menunjukkan bahwa rata-rata responden mengatakan tidak memiliki gejala penyakit diare sekitar $80 \%$ dari total responden dan persentase tertinggi untuk responden yang mengatakan memiliki penyakit diare pada anak remaja laki-laki sebesar $20,3 \%$ dari total responden.

Tabel 5. Kejadian Penyakit Diare pada Penduduk Berdasarkan Waktu Terkena Diare

\begin{tabular}{|c|c|c|c|c|c|c|c|c|c|}
\hline \multirow{3}{*}{ Kategori } & \multirow{3}{*}{ Variabel } & \multicolumn{6}{|c|}{ Strata Desa/Kelurahan } & \multicolumn{2}{|c|}{ Total } \\
\hline & & \multicolumn{2}{|l|}{1} & \multicolumn{2}{|l|}{2} & \multicolumn{2}{|l|}{3} & \multirow[b]{2}{*}{$\mathrm{N}$} & \multirow[b]{2}{*}{$\%$} \\
\hline & & $\mathrm{n}$ & $\%$ & $\mathrm{n}$ & $\%$ & $\mathrm{n}$ & $\%$ & & \\
\hline \multirow{8}{*}{$\begin{array}{l}\text { Waktu paling dekat } \\
\text { anggota keluarga ibu } \\
\text { terkena diare }\end{array}$} & Hari ini & 0 & 0 & 2 & 1 & 3 & 2,6 & 5 & 1,4 \\
\hline & Kemarin & 2 & 4,4 & 2 & 1 & 1 & 0,9 & 5 & 1,4 \\
\hline & 1 minggu terakhir & 2 & 4,4 & 11 & 5,5 & 13 & 11,3 & 26 & 7,2 \\
\hline & 1 bulan terakhir & 6 & 13,3 & 15 & 7,5 & 5 & 4,3 & 26 & 7,2 \\
\hline & 3 bulan terakhir & 9 & 20 & 45 & 22,5 & 7 & 6,1 & 61 & 16,9 \\
\hline & 6 bulan yang lalu & 5 & 11,1 & 32 & 16 & 9 & 7,8 & 46 & 12,8 \\
\hline & $\begin{array}{l}\text { Lebih dari } 6 \text { bulan } \\
\text { yang lalu }\end{array}$ & 8 & 17,8 & 53 & 26,5 & 33 & 28,7 & 94 & 26,1 \\
\hline & Tidak pernah & 13 & 28,9 & 40 & 20 & 44 & 38,3 & 97 & 26,9 \\
\hline
\end{tabular}

Tabel 6. Kategori Penyakit Diare pada Penduduk Berdasarkan Usia dan Jenis Kelamin

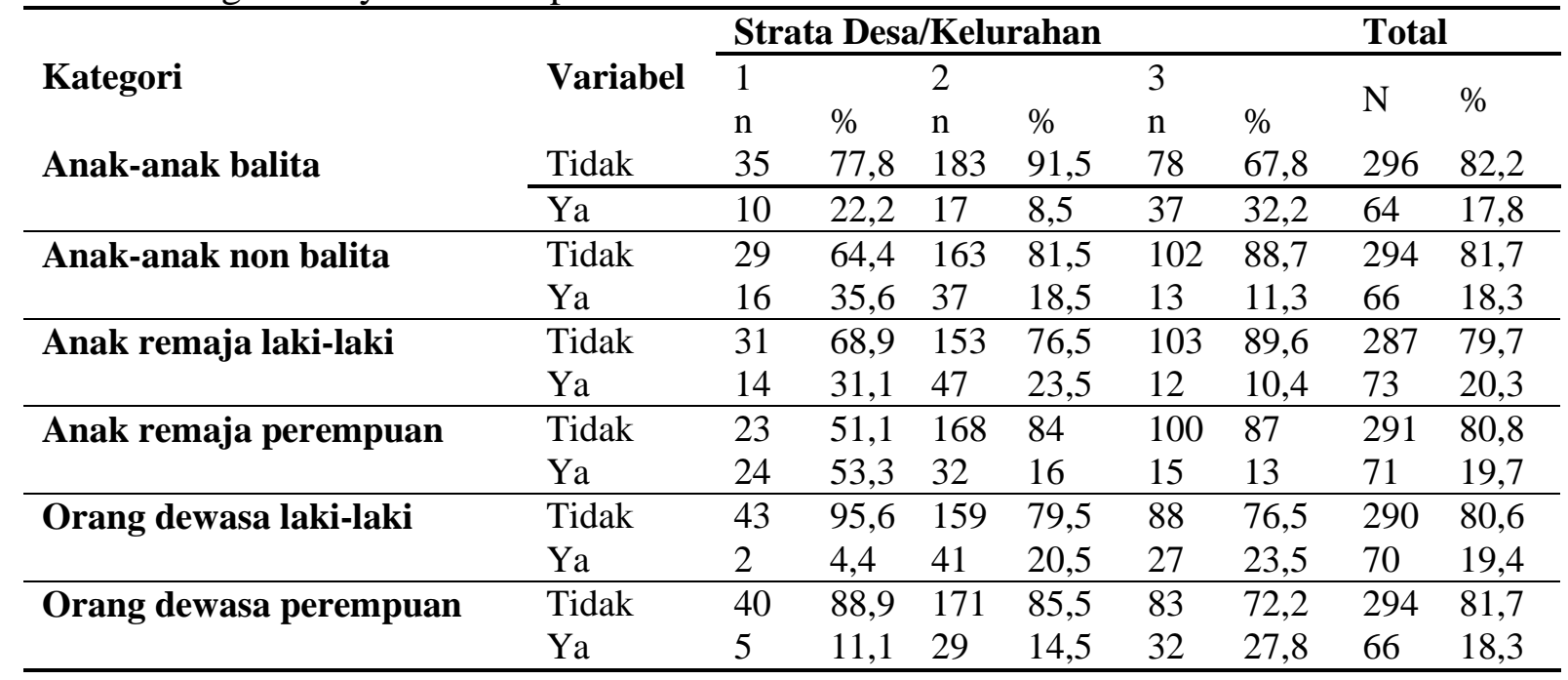


Penelitian yang serupa juga dilakukan oleh Semba, dkk (2011), mengatakan anak dari keluarga tidak memiliki jamban akan berisiko 1,32 kali terkena diare parah yang tingkat kematian balita sebesar 1,43 kali. Perilaku buang air besar sembarangan dapat dipengaruhi dengan berbagai faktor.

\subsection{Indeks Risiko Sanitasi Lingkungan (IRS) Kecamatan Abiansemal}

Penurunan terhadap kualitas tubuh, kesehatan, dan lingkungan akibat minimnya akses seperti layanan sektor sanitasi dan PHBS dapat disebut sebagai risiko sanitasi. Manfaat dari penghitungan Indeks Resiko Sanitasi (IRS) yaitu sebagai komponen penentu untuk area yang beresiko sanitasi.

Tabel 7. Tabel Indeks Risiko Sanitasi Kecamatan Abiansemal 2019

\begin{tabular}{|c|c|c|c|c|}
\hline \multirow{9}{*}{ 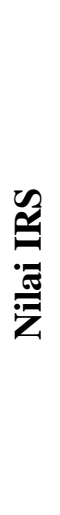 } & & \multicolumn{3}{|c|}{ Strata } \\
\hline & & Strata 1 & Strata 2 & Strata 3 \\
\hline & Genangan Air & 13 & 10 & 8 \\
\hline & Persampahan & 33 & 43 & 35 \\
\hline & $\begin{array}{l}\text { Perilaku Hidup Bersih dan Sehat } \\
\text { (PHBS) }\end{array}$ & 28 & 32 & 28 \\
\hline & Air Limbah Domestik & 36 & 40 & 45 \\
\hline & Sumber Air Rumah Tangga & 31 & 36 & 33 \\
\hline & Total & 141 & 161 & 149 \\
\hline & Kategori & Kurang Beresiko & Resiko Tinggi & Resiko Sedang \\
\hline
\end{tabular}

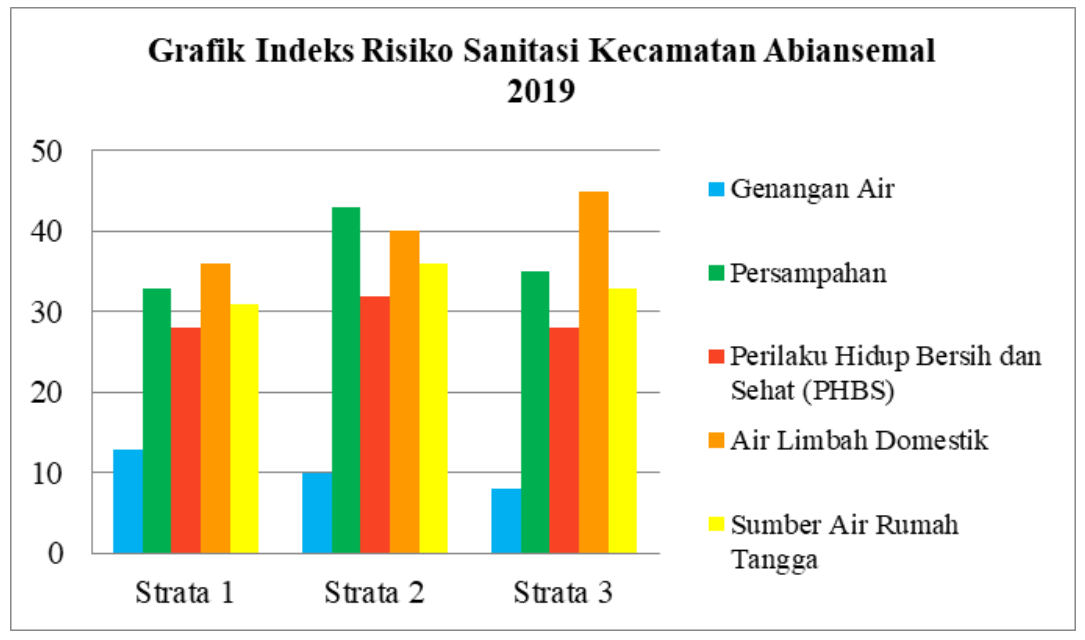

Gambar 3.

Grafik Indeks Risiko Sanitasi Kecamatan Abiansemal 2019

Tabel 7 dan Gambar 2 memberikan gambaran kondisi sanitasi berdasarkan studi EHRA, dapat disimpulkan beberapa permasalahan utama pada tiap strata adapun penjabaran permasalahan tersebut adalah sebagai berikut: Strata 1 terdiri dari 1 desa memiliki permasalahan utama limbah domestik dengan skor tertinggi 36, kemudian persampahan dengan skor 33, sumber air dengan skor 31 , dilanjutkan permasalahan perilaku hidup bersih dan sehat dengan skor 28 dan genangan/banjir dengan skor 13 . Strata 2 yaitu terdiri dari 11 desa memiliki ECOTROPHIC • 15(2): 191-203 p-ISSN:1907-5626,e-ISSN: 2503-3395 permasalahan utama persampahan dengan skor 43, kemudian air limbah domestik dengan skor 40, dilanjutkan lalu permasalahan sumber air dengan skor 36 , permasalahan perilaku higiene dan sanitasi sebesar 32 dan genangan/ banjir dengan skor 10 . Strata 3 yaitu terdiri dari 6 desa memiliki permasalahan utama air limbah domestik dengan skor 45 , kemudian persampahan dengan skor 35, sumber air dengan skor 33, perilaku higiene dan sanitasi dengan skor 28 dilanjutkan permasalahan genangan/ banjir dengan skor 8 . 
Tabel 8. Hasil scoring EHRA Kecamatan Abiansemal

\begin{tabular}{|c|c|c|c|c|c|c|c|c|c|}
\hline & \multirow[b]{2}{*}{ 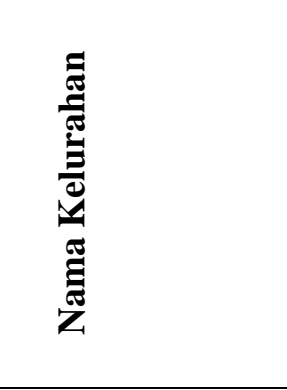 } & \multicolumn{5}{|c|}{ Nilai IRS } & \multirow[b]{2}{*}{ है } & \multirow[b]{2}{*}{ 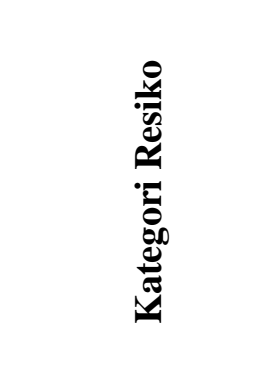 } & \multirow[b]{2}{*}{$\frac{\ddot{0}}{\dot{s}}$} \\
\hline & & 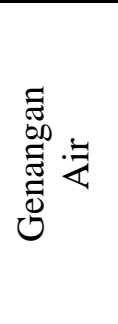 & 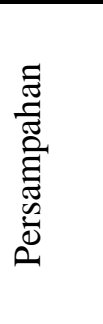 & 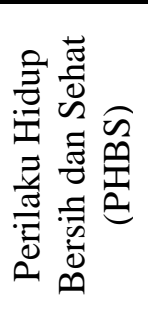 & 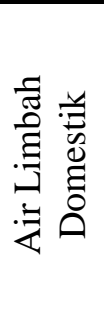 & 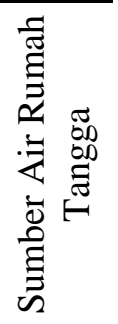 & & & \\
\hline $\begin{array}{c}\text { Strata } \\
1\end{array}$ & Sibang Gede & 13 & 33 & 28 & 36 & 31 & 142 & Kurang Beresiko & 1 \\
\hline \multirow{11}{*}{$\begin{array}{c}\text { Strata } \\
2\end{array}$} & Darmasaba & 10 & 43 & 32 & 40 & 36 & 161 & Resiko Tinggi & 3 \\
\hline & Jagapati & 10 & 43 & 32 & 40 & 36 & 161 & Resiko Tinggi & 3 \\
\hline & Angantaka & 10 & 43 & 32 & 40 & 36 & 161 & Resiko Tinggi & 3 \\
\hline & Sibang Kaja & 10 & 43 & 32 & 40 & 36 & 161 & Resiko Tinggi & 3 \\
\hline & Mekar Bhuwana & 10 & 43 & 32 & 40 & 36 & 161 & Resiko Tinggi & 3 \\
\hline & Dauh Yeh Cani & 10 & 43 & 32 & 40 & 36 & 161 & Resiko Tinggi & 3 \\
\hline & Ayunan & 10 & 43 & 32 & 40 & 36 & 161 & Resiko Tinggi & 3 \\
\hline & Blahkiuh & 10 & 43 & 32 & 40 & 36 & 161 & Resiko Tinggi & 3 \\
\hline & Punggul & 10 & 43 & 32 & 40 & 36 & 161 & Resiko Tinggi & 3 \\
\hline & Bongkasa & 10 & 43 & 32 & 40 & 36 & 161 & Resiko Tinggi & 3 \\
\hline & Sangeh & 10 & 43 & 32 & 40 & 36 & 161 & Resiko Tinggi & 3 \\
\hline \multirow{6}{*}{$\begin{array}{c}\text { Strata } \\
\mathbf{3}\end{array}$} & Sedang & 8 & 35 & 28 & 45 & 33 & 149 & Resiko Sedang & 2 \\
\hline & Mambal & 8 & 35 & 28 & 45 & 33 & 149 & Resiko Sedang & 2 \\
\hline & Abiansemal & 8 & 35 & 28 & 45 & 33 & 149 & Resiko Sedang & 2 \\
\hline & Taman & 8 & 35 & 28 & 45 & 33 & 149 & Resiko Sedang & 2 \\
\hline & Selat & 8 & 35 & 28 & 45 & 33 & 149 & Resiko Sedang & 2 \\
\hline & Bongkasa Pertiwi & 8 & 35 & 28 & 45 & 33 & 149 & Resiko Sedang & 2 \\
\hline
\end{tabular}

Keterangan Area Beresiko

\begin{tabular}{|lll|}
\hline Kurang Beresiko & $(138-147)$ & 1 \\
Resiko Sedang & $(148-157)$ & 2 \\
\hline Resiko Tinggi & $(158-167)$ & 3 \\
\hline Resiko Sangat Tinggi & $(168-176)$ & 4 \\
\hline
\end{tabular}

Tabel 8 menunjukkan hasil analisa IRS kategori area berisiko rendah/ kurang beresiko pada anggota Srata 1 yang memiliki skor 142, dengan risiko sanitasi paling tinggi merupakan air limbah domestik 36, persampahan sebesar 33, sumber air rumah tangga dengan skor 31 , PHBS 28, dan sumber air serta genangan air 13. Kategori area berisiko tinggi pada anggota Strata 2 memiliki nilai/skor 161 degan risiko sanitasi paling tinggi adalah masalah persampahan dengan skor 43, air limbah domestik dengan skor 40, kemudian permasalahan sumber air rumah tangga 36 , permasalahan perilaku higiene dan sanitasi sebesar 32 lalu permasalahan genangan/ banjir dengan skor 10. Kategori area berisiko sedang ada pada anggota Strata 3 yang memiliki nilai/skor 149, dengan risiko sanitasi paling tinggi adalah air limbah domestik sebesar 45, persampahan 35, sumber air rumah tangga 33, perilaku higiene dan sanitasi dengan skor 28, lalu permasalahan genangan/ banjir dengan skor 8.

Pendidikan perilaku didapatkan dalam keluarga, karena di dalam sebuah keluarga akan memiliki komunikasi serta interaksi yang 
akan meningkatkan kualitas kesehatan masyarakat. Penerapan PHBS sedini mungkin dalam keluarga bisa mewujudkan keluarga yang sehat dan aktif pada setiap usaha kesehatan dalam masyarakat. Peningkatan presentase rumah tangga yang melakukan PHBS dilakukan Pusat Promosi Kesehatan Kemenkes untuk meningkatkan kesehatan anggota keluraga.

\section{SIMPULAN DAN SARAN}

\subsection{Simpulan}

Pengelolaan sampah di Kecamatan Abiansemal yang dianalisis menggunakan metode EHRA menyatakan bahwa pengelolaan sampah di Kecamatan Abiansemal masih belum memadai. Pada pembuangan limbah air tinja manusia dan lumpur tinja dari hasil studi EHRA masih dinyatakan dalam kondisi aman dan drainase menunjukkan tidak ada genangan (aman banjir). Pada pengelolaan air minum rumah tangga dinyatakan sudah cukup memadai dan terkait perilaku hygiene dan sanitasi masyarakat, sebanyak $57,6 \%$ responden mengatakan CTPS di lima waktu tidak penting, namun hasil tersebut dinyatakan tidak berisiko karena pada variabel perilaku hygiene dan sanitasi lainnya masih dinyatakan aman, sedangkan kejadian penyakit diare selama 6 bulan kebelakang di Kecamatan Abiansemal menunjukkan persentase yang rendah.

Hasil analisa indeks risiko sanitasi kategori area berisiko rendah/kurang beresiko pada anggota strata 1 (1 desa) dengan nilai/skor 142, kategori area berisiko tinggi pada anggota Strata 2 (11 desa) dengan nilai/skor 161 dan kategori area berisiko sedang ada pada anggota strata 3 (6 desa) dengan nilai/skor 149 .

\subsection{Saran}

Pelaksanaan dari studi EHRA akan optimal, jika melakukan beberapa saran antara lain: Kepada Dinas Kesehatan Kabupaten Badung diharapkan melakukan studi EHRA secara berkala dan melakukan penyuluhan kepada masyarakat tentang pentingnya kesehatan sanitasi dan lingkungan; Kepada masyarakat agar dapat meningkatkan kualitas sanitasi dan selalu menerapkan pola hidup bersih dan sehat; dan pada peneliti studi EHRA yang akan datang agar dapat mengembangkan studi EHRA seperti penambahan beberapa variabel yaitu permeabilitas dan porositas tanah, arah aliran tanah, jenis dan jumlah sumber pencemar dan kedalaman permukaan air tanah agar hasil yang diperoleh lebih spesifik.

\section{DAFTAR PUSTAKA}

Badan Perencanaan Pembangunan Nasional. 2006. Petunjuk Teknis Pengajuan Usulan Kegiatan Yang Dibiayai Dari Pinjaman Dan/Atau Hibah Luar Negeri. Jakarta.

BPS Kabupaten Badung. 2020. Abiansemal Dalam Angka 2020. Badan Pusat Statistik Kabupaten Badung.

BPS Kabupaten Badung. 2021. Abiansemal Dalam Angka 2021. Badan Pusat Statistik Kabupaten Badung.

Curtis. 2001. Evidence of behaviour change following a hygiene promotion programme in Burkina Faso. Bulletin of the World Health Organization. Vol. 79 (6): 00429686.

Hasibuan, Rosmidah. 2016. Analisis Dampak Limbah/Sampah Rumah Tangga Terhadap Pencemaran Lingkungan Hidup. Jurnal Ilmiah "Advokasi" Vol. 04. No. 01. Nomor 2337-7216

Indonesia Urban Water, Sanitation, and Hygiene (IUWASH). 2011. Sanitasi dan Kebersihan Perkotaan Indonesia. Sulawesi Selatan.

ISSDP. 2007. Penilaian Resiko Kesehatan Lingkungan Kota Blitar. Jakarta: Indonesia Sanitation Sector Development Program.

Kumala, 2011. Meningkatkan Pengetahuan, Sikap dan Perilaku Ibu dalam Tatalaksana diare. Yogyakarta: Pustaka Belajar http://www.ampl.or.id/digilib/read/pend erit a-diare-meningkat/46677. Diakses Tanggal 15 Juli 2021. 
Penilaian Risiko Kesehatan Lingkungan...

Rahma, S. 2003. Faktor-Faktor Yang Berhubungan Dengan Kejadian Kecacingan Pada Anak SD Di SD Bustanul Islamiyah. [Tesis]. Pascasarjana Universitas Hasanuddin. Makassar.

Semba, R, et al. 2011. Relationship of the Presence of a Household Improved Latrine with Diarrhea and Under-Five Child Mortality in Indonesia. The American Society of Tropical Medicine and Hygiene. Vol. 84. No. 3. p. 443-50.
[Ni Ketut Sri Lestari, dkk]

Sudaryat, Suraatmaja. 2007. Kapita Selekta Anak. Jakarta

Suripin. 2004. Sistem Drainase Perkotaan yang Berkelanjutan. Yogyakarta: Andi

Tim National Geographic. 2013. Indonesia Negara dengan Sanitasi Terburuk Kedua di Dunia. [Online]. [Diakses 29 Januari 2021].

http://nationalgeographic.co.id/berita/20 13/10/indonesianegara-dengan-sanitasiterburuk-kedua-di-dunia 